tracheal system consists, on the whole, of arborescent branching of the system present in the first instar, but there also occur some remarkable changes of atrophy; for example, the dorsal-longitudinal tracheal trunk, which at first does not open directly into the ventral-longitudinal tracheal trunk, finally does so, and its end portions atrophy. The final number of the tracheal branches (in the pupa) is constant and is 156. There is a gradual shifting backwards of the tracheal system with reference to the body segments. Some of the tracheal branches in the pupa which are apparently homologous actually develop hetrochronously.

The breathing folds are just visible in the first instar (except the posterior one which first makes its appearance in the third instar); their growth consists in the deepening of the furrows, the development of papillæ on the roof and the formation of elaborate marginal openings.

The detailed results of this investigation will appear elsewhere.

Department of Zoology,

University of Lucknow and

Zoological Laboratory, Cambridge.

${ }^{1}$ Canadian Entomologist, 33 ; 1901.

\section{The Government and Inland Water Survey}

I AM glad to see that the observations expressed in the leading article in Nature of August 4 represent so clearly and unmistakably the views of the British Association Research Committee, of which I am chairman.

It may be added that on the occasion of the deputation to Sir Hilton Young, I directed his attention to the fact that our Committee comprises not only competent engineers and scientific experts of independent standing, but also technical representatives of the various Government departments interested (including the Ministry of Health), these gentlemen, although not officially nominated, being co-opted with the cognisance and approval of the departments concerned.

It is to be hoped, when the suggestions made by the deputation are receiving "the most careful consideration of the Government" promised by the Minister of Health, that the advice tendered by these technical officers will not be ignored, and that the Government will consequently be able to view the matter in its proper light and agree to action being taken along the lines indicated, without undue delay.

Aug. 4 .

H. P. Douglas.

\section{Discovery of a Fossil Elephant in Palestine}

QUITE recently a discovery of remains of an extinct elephant has been made in Palestine. This is the first time that such remains have been discovered there, nor have they yet occurred in Syria, and it will be of interest to see if this find has any connexion with the faunas of so-called African type which have been found in several Palestinian caves associated with a Mousterian culture and human remains.

The newly found specimens were obtained in digging a well in a garden at Bethlehem, but unfortunately the value of the remains was not at first recognised, and thus, except for a section of tusk $8 \mathrm{~cm}$. in length, the bones and teeth are in a very fragmentary condition. During a recent stay in Jerusalem, I was able, with the co-operation of the Museum authorities, to collect a few more fragments from the material dug out of the well. All the specimens have now been sent by the Department of Antiquities of Palestine to the British Museum (Natural History) for study. It is hoped that a detailed description of these remains will shortly be published, and that it may be possible for further excavations to be made at this locality. The deposit in which these elephant remains occur is doubtless Pleistocene, but information as to the precise age of the beds is still needed.

Department of Geology,

Dorothea M. A. Bate.

British Museum (Natural History). Aug. 3.

\section{Luminous Night Clouds}

ON the night of June 30-July 1 large masses of night clouds were seen over southern Norway, travelling with great velocity from east to west. Three of my aurora stations, Oslo, Kongsberg and Toemte, were in action, and a series of simultaneous photographs were taken from all three stations. By inspecting the plates, one gets the impression that the height was of the same order, about $80 \mathrm{~km}$., as in 1932, but details can only be given when the plates are measured and calculated.

It would be interesting to know if the clouds have been seen in other countries. Probably they will appear again and a look-out for them is very desirable.

On account of their great height, they may perhaps disturb radio propagations, and observations in this respect would be very interesting.

Dröbak, near Oslo.

CARL StÖRMER. July 10.

\section{Hostility of Starlings to Swallows}

HAs any special enmity of starlings against swallows been observed? If so, what is the reason suggested for it ?

In my garden is a little lake, a shallow reach of which is largely used as a bath and for drinking by a great variety of birds, including starlings. A few swallows (Hirundo rustica) also skim the lake frequently for insects; and occasionally alight each day on one or other of the stones on the bank preliminary to drinking. Whenever a swallow thus alights whilst any starlings are near, one or more of the latter immediately rush viciously at the swallow, trying to peck it and driving it off. On the other hand, none of the many other frequenting birds, and not even the pugnacious blackbirds and sparrows, exhibit any hostility to these inoffensive, graceful visitors. Nor do the starlings, so quarrelsome amongst themselves, habitually drive off other birds than the swallows, but feed amongst many of them, although the latter are searching for the same food as themselves, worms, insects and beetles. Hence the motive of this hostility does not appear to be based on the food problem, or envy at the superior agility of the swallow in catching insect food on the wing.

Ardsloy, Craigmore, L. A. WADDELL. July 9 . 